\title{
Rechtsgeschichte
}

http://www.rg-rechtsgeschichte.de/rg1

Zitiervorschlag: Rechtsgeschichte Rg 1 (2002)

Rg $12002 \quad 304-304$

http://dx.doi.org/10.12946/rg01/304-304

Reihe Unwissen / Joint Venture 


\section{Reihe Unwissen}

Ralph-Johannes Lilie, Byzanz. Geschichte des Oströmischen Reiches (Wissen in der Beck'schen Reihe, 2085), München: Beck I999 und 2. Aufl. 200I, S. 42:

"Justinian sah sich als Erneuerer des Römischen Reiches, und er beschränkte dies nicht auf die Rückeroberung der verlorenen Reichsteile, sondern suchte das Reich auch im Inneren zu reformieren. Auf seine Anordnung hin entstand das Corpus Iuris, eine Sammlung aller Gesetze und Entscheide bis in seine eigene Zeit. Während die Digesten im wesentlichen eine Kompilation aus früheren Rechtskodifikationen darstellen, besonders aus dem sog. Codex Theodosianus, bilden die etwas später entstandenen Novellen eine systematische Sammlung zeitgenössischer Rechtsprechung, die im Gegensatz zu den lateinischen Digesten auf Griechisch niedergelegt wurden."

\section{Joint Venture}

International Max Planck Research School for comparative european legal history

Gegenwärtigen Fusionspraktiken folgend, haben auch Rechtshistoriker sich verbündet, um international Synergien zu erzeugen. Das Max-Planck-Institut für europäische Rechtsgeschichte und das Institut für Rechtsgeschichte an der Johann Wolfgang Goethe-Universität haben - mit dem Segen und dem Geld ihrer »Mütter « ein gemeinsames Forschungskolleg gegründet.

Am I. Oktober 2002 startet in Frankfurt am Main die International Max Planck Research School for comparative european legal history.

Die Research School bietet Nachwuchswissenschaftlern (Doktoranden, Habilitanden) aus aller Welt Gelegenheit, sich der Rechtsgeschichte im Verbund von Lehrenden und Lernenden, in einem internationalen Ambiente, in Seminarien und bei Vorträgen, in gemeinschaftlichen Projekten und Diskussionsrunden zu widmen und in Freiheit, aber nicht in Einsamkeit zu forschen.

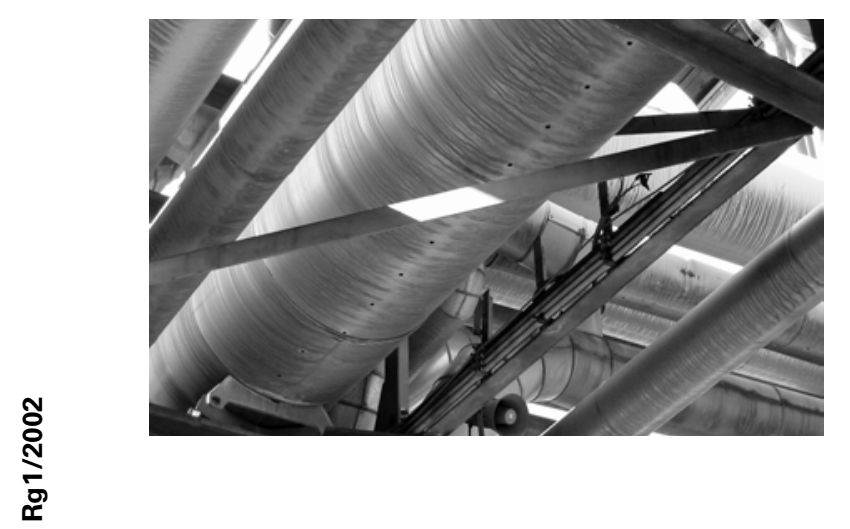

Reihe Unwissen, Joint Venture
Die Research School kann (in der Regel einjährige) Stipendien vergeben. Bewerbungen werden $\mathrm{ab}$ sofort entgegengenommen und sind - mit Curriculum Vitae und Projektskizze - an einen der derzeitigen Sprecher der Research School zu richten:

Prof. Dr. Albrecht Cordes

Institut für Rechtsgeschichte

Fachbereich Rechtswissenschaft

Johann Wolfgang Goethe-Universität

Postfach II I9 32

D-60054 Frankfurt am Main

cordes@jur.uni-frankfurt.de

Prof. Dr. Dr.h.c. Michael Stolleis

Max-Planck-Institut für europäische

Rechtsgeschichte

Postfach 930227

D-60457 Frankfurt am Main

stolleis@mpier.uni-frankfurt.de

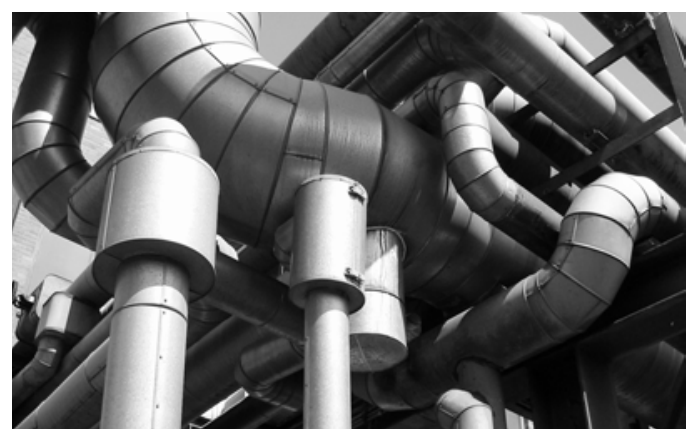

